\title{
A Comparison of Three-Dimensional and Two-Dimensional Cephalometric Evaluations of Children with Cleft Lip and Palate
}

\author{
Ozlem Tulunoglua \\ Elcin Esenlik ${ }^{b}$ \\ Ayse Gulsenc \\ Ibrahim Tulunoglud
}

\begin{abstract}
Objectives: The aim of this retrospective study was to compare the consistency of orthodontic measurement performed on cephalometric films and 3D CT images of cleft lip and palate (CLP) patients.

Methods: The study was conducted with 2D radiographs and 3D CT images of 9 boys and 6 girls aged 7-12 with CLP. 3D reconstructions were performed using MIMICS software.

Results: Frontal analysis found statistical differences for all parameters except occlusal plane tilt (OcP-tilt) and McNamara analysis found statistical differences in 2D and 3D measurements for all parameters except ANS-Me and Co-Gn; Steiner analysis found statistical differences for all parameters except SND, SNB and Max1-SN. Intra-group variability in measurements was also very low for all parameters for both 2D and 3D images.

Conclusions: Study results indicate significant differences between measurements taken from 2D and 3D images in patients with cleft lip and palate. (Eur J Dent 2011;5:451-458)
\end{abstract}

Key words: 3D reconstruction; Computerized tomography; Cephalometry; CLP.

a Department of Pediatric Dentistry, Faculty of Dentistry, Gazi University, Ankara, Turkey.

b Department of Ortodontics, Faculty of Dentistry, Suleyman Demirel University, Isparta, Turkey. Department of Plastic and Reconstructive Surgery, Faculty of Medicine, Gazi University, Ankara, Turkey.

d Department of Prosthodontics, Faculty of Dentistry, Hacettepe University, Ankara, Turkey.

- Corresponding author: Dr. Elcin Esenlik Suleyman Demirel Universitesi, Dis Hekimligi Fakultesi, Ortodonti A.B.D, Cunur, Isparta, 32260, Turkey.

Phone: +902462118807

Fax: +90 2462370607

E-mail: elcinesda yahoo.com

\section{INTRODUCTION}

Conventional cephalometry is an inexpensive and essential method for evaluating orthodontic patients. ${ }^{1,2}$ However, it is difficult to evaluate patients with major craniofacial deformities, in particular facial asymmetry, using conventional cephalometry. ${ }^{1}$ For this reason, three-dimensional computed tomography (3D-CT) imaging is widely used in the diagnosis and surgical treatment planning of patients with craniofacial deformities. ${ }^{3-5}$ 3D-CT data is especially helpful in evaluating pa- 
tients with asymmetry because they do not suffer from the magnification- and distortion-related problems inherent in $2 \mathrm{D}$ projections.

With the general trend away from traditional 2D cephalometric analysis towards new 3D techniques, it is helpful to compare the use of different applications in various settings. ${ }^{6,7}$ A study conducted by Kragskov et al $^{1}$ comparing lateral and frontal cephalograms and CT scans of human dry skulls found lateral cephalograms to be more reliable than 3D-CT, with less than $1 \mathrm{~mm}$ of variation between observers for most points, compared to about $2 \mathrm{~mm}$ for 3D-CT images. Differences between 3D-CT and frontal cephalograms were less obvious. They also stated that, frontal cephalometrics showed significantly less inter-observer variation, and for standard lateral and frontal cephalometric points, there is no evidence that $3 D-C T$ is more reliable than the conventional cephalometric methods in normal skull. ${ }^{1}$ However, conventional cephalometrics are inadequate for assessing patients with severe asymmetric craniofacial syndromes; therefore, 3D-CT cephalometrics are indicated in such patients. ${ }^{1,8}$

Adams et $\mathrm{al}^{8}$ found 3D evaluation to be more precise than $2 \mathrm{D}$ evaluation. Their results indicate that, when the actual distance is measured on a human skull in its true dimensions of 3D space, is more precise and 4 to 5 times more accurate than the $2 \mathrm{D}$ approach. ${ }^{8}$ Various authors have stated that in patients with clefts, 3D imaging provides a better understanding of bone and soft-tissue defects than 2D imaging. ${ }^{1,8-10}$

Most patients requiring routine orthodontic treatment do not require successive CT scans. However, predicting growth is very important in patients with severe soft and bony tissue defects, especially in cases where repeated surgical intervention or reconstruction is envisaged. ${ }^{11}$ In such cases, patients needed to be followed closely so that surgeons can track the changes that occur between examinations in order to ensure accurate planning and successful intervention. ${ }^{12,13}$

The MIMICS 10.02 (Materialise, Belgium) software program has advanced features that perform $3 \mathrm{D}$ reconstruction of $\mathrm{CT}$ data as well as most types of anthropometric analysis. There are several studies on patients with severe craniofacial defects using software allowing 3D reconstruction of CT scan data and anthropometric analyses, reporting conflicting findings on the advantages and disadvantages of the usage of software versus cephalometric analyses performed on conventional two dimensional lateral cephalography. ${ }^{1,5,8,13,14}$

This retrospective study aimed to compare McNamara, Steiner and Frontal analyses performed using conventional 2D lateral and frontal cephalometric radiograms and 3D CT images in a population of children aged 7-12 years with cleft lip and palate.

\section{MATERIALS AND METHODS}

Study participants were selected from among the 118 patients treated for CLP at the Medical Faculty's Department of Reconstructive and Plastic Surgery between 2005-2009. Of these, 21 patients had lateral and frontal cephalometric films and $3 D$ CT images in the department archives; however, 6 patients were excluded because of the time lapse (3-6 months) between when the cephalograms and 3D CT images were obtained. In total, orthodontic analysis was performed using radiograms and cranial CT images of 15 children with CLP 9 boys, 6 girls; age range: 7-12 years).

CT scans (Discovery, General Electric's, USA) were obtained using a strict, standardized protocol, with the patient in a horizontal position and the patient's head positioned with the help of a head positioner. Three-dimensional reconstruction and orthodontic measurement were performed using the MIMICS software program (MIMICS 10.02, Materialise, Belgium).

Standard lateral and frontal cephalograms were taken at the same magnification with the same equipment using a cephalostat incorporated into a conventional $x$-ray device (Proline 2002, Planmeca OY, Finland). Cephalometric films were traced using a protractor with an accuracy of $0.5 \mathrm{~mm}$ and $0.5^{\circ}$. All landmark identification and analysis was performed by the same orthodontist, and measurements were repeated after 15 days to control for examiner error. For some symmetrical parameters (Co-Gn, Co-A, SN-Go-Gn, SpPo-GoMe) mean values of left- and right-side measurements from 3D images were calculated in order to compare 2D and 3D measurements. McNamara, Steiner and Frontal analyses landmarks included in Mimics software program were measured. Measurements included both vertical and antero-posterior components of the craniofacial form. 


\section{Statistical analysis}

All statistical analysis was carried out using the statistical software package SPSS version 11.5 (SPSS Inc., Ill, USA). Mann Whitney U tests was performed to identify differences between the $2 \mathrm{D}$ and $3 \mathrm{D}$ groups, with a level of significant set at $P<.05$. Intra-class correlation (ICC) coefficients were calculated to determine the reliability of measurements.

\section{RESULTS}

ICC coefficients were very high for both $2 \mathrm{D}$ (0.94-0.99) and 3D measurements (0.88-0.99). Results of Frontal, McNamara and Steiner analyses are given, respectively, in Tables 1, 2 and 3. Frontal analysis found all parameters except for OcPtilt to be significantly higher in the $2 \mathrm{D}$ group when compared to the $3 \mathrm{D}$ group. McNamara analysis found no differences between ANS-Me and Co-Gn measurements in the 2D and $3 \mathrm{D}$ groups; however, Co-A was significantly higher $(\mathrm{P}<.01)$ and MaxilloMandibular difference (max-mand) and SpPoGoMe were significantly lower $(\mathrm{P}<.05$ and $\mathrm{P}<.001$, respectivelyl in the $3 \mathrm{D}$ group when compared to the 2D group. Steiner analysis found no significant differences between 2D and 3D groups for the parameters SNB, SND and Max1-SN; however, ANB, Mand1-NB, Max1-NA, SNGoGN and SNA were significantly greater and interincisal angle (1-1) significantly smaller in the 3D group when compared to the $2 \mathrm{D}$ group.

\section{DISCUSSION}

CT allows for the measurement of real lengths and angles that is not available with conventional 2D cephalometry. Furthermore, 3D CT makes it possible to assess age-related changes and postsurgical changes in patients with facial deformity, regardless of differences in patient position between examinations. ${ }^{1,15}$ Studies have shown that the additional spatial information provided by $3 \mathrm{D}$ analysis makes it possible to obtain a more accurate assessment of the formation, position, characteristics and dimensions of facial soft tissue as well as the eruption of permanent teeth in all patients using 3D images rather than standard 2D methods. ${ }^{4,16}$ Craniofacial CT analysis has also been reported to be an excellent method for quantifying and analyzing surface and deep craniofacial structures, especially in cleft palate patients. ${ }^{17}$
While CT is not routinely recommended, it is helpful in those rare cases where plain films may not be reliable enough to assist in making clinical decisions. ${ }^{18}$

Errors related to projection, landmark identification and measurement technique can affect the accuracy of measurements taken from frontal cephalograms. ${ }^{19}$ Probably the most important problem of the PA cephalogram is differential magnification; however, correction of differential magnification is neither widely understood nor routinely practiced..$^{20}$ Lateral cephalometric films have been reported to have similar magnification problems. ${ }^{21}$ In line with earlier studies ${ }^{22} 2 \mathrm{D}$ PA cephalogram measurements were statistically larger than 3D measurements for all parameters (with the exception of OcP-tilt), with the most noticeable difference $(14 \mathrm{~mm})$ in the parameter ZA-AZ. These differences are likely the result of magnification error. Vlijmen et $\mathrm{al}^{22}$ found statistically significant differences between conventional frontal cephalometric radiographs and CBCT-constructed 3D models for all measurements except antegonial notch and left lateral orbital margin. The authors explained the discrepancies as resulting from differences in how the landmarks are viewed in $2 \mathrm{D}$ images (on a single tomographic plane) and 3D images (on multiple planes). For this reason, comparison of $2 D$ and $3 D$ images should be undertaken with great caution.

Reproducing head posture and errors in identifying landmarks have also been shown to be problematic with posteroanterior cepahlograms. ${ }^{23-25}$ Major et $\mathrm{al}^{25}$ found that rotation of the vertical axis did not affect the relationship of landmarks to the best horizontal line, but did affect their relationship to the best vertical line. In a study conducted with dry skulls, van Vlijmen et $\mathrm{al}^{26}$ showed that patient position, i.e., head tilt/rotation, can significantly influence measurements in frontal cephalometric analysis, and Malkoç et a ${ }^{27}$ similarly reported that head rotation is likely to affect both linear and angular measurements in lateral cephalometric analysis. In the present study, most parameters (SN-GoGn, ANB, SNA, Max1-NA, Mand1-NB and interincisal angle) varied significantly between the lateral cephalograms and the 3D images. The higher values in the 2D group may be the result of head rotation and magnification error with the lateral cephalograms. Moreover, the complex struc- 
ture of CLP makes it difficult to define this region in cephalometric films.

In a study of 6 human dry skulls comparing cephalometric radiographs and CT imaging processed using Mimics, Varghese et $\mathrm{al}^{14}$ found linear measurements on spiral CT images to be comparable to anatomical measurements and more reliable than cephalometric measurements, which were acceptable for the midsagittal region in the anteroposterior plane, but which varied significantly from anatomical and CT measurements of most parameters. Another study on dry skulls by Major et al ${ }^{28}$ regarding the posteroanterior cephalometric films. Given that landmark identifica- tion is easier on dry skulls devoid of soft tissue, it is likely that the results of the above-mentioned studies represent the minimum error and for this reason differences of up to four times greater have been reported for some measurements in the presence of soft tissue..$^{30}$

The clinical significance of measurement accuracy varies depending upon the level of accuracy required. For example, if CT data is used for pre-surgical planning, information needs to be sufficiently accurate to prevent surgical interventions that result in insufficient jaw lengthening or shortening that might require additional surgery. Despite the difficulty in accurately identify-

Table 1. Comparison of 2D and 3D cephalometric evaluation for Frontal analysis.

\begin{tabular}{|c|c|c|c|c|c|}
\hline Parameters & Mean \pm Std. Dev & Median & Minimum & Maximum & test \\
\hline B3L-B3R (mm) CEPH & $27.41 \pm 3.56$ & 28.00 & 23.00 & 34.00 & \multirow{2}{*}{$P<.012^{*}$} \\
\hline B3L-B3R $(\mathrm{mm}) 3 D$ & $25.43 \pm 2.00$ & 24.72 & 22.90 & 28.87 & \\
\hline B6L-B6R (mm) CEPH & $54.00 \pm 6.96$ & 53.00 & 42.50 & 64.50 & \multirow{2}{*}{$\mathrm{P}<.01^{* *}$} \\
\hline B6L-B6R (mm) 3D & $47.33 \pm 3.26$ & 46.37 & 43.74 & 52.98 & \\
\hline $\operatorname{ImL}-\operatorname{ImR}(\mathrm{mm}) \mathrm{CEPH}$ & $82.91 \pm 6.87$ & 84.00 & 72.00 & 92.00 & \multirow{2}{*}{$P<.03^{*}$} \\
\hline $\operatorname{ImL}-\operatorname{ImR}(\mathrm{mm}) 3 \mathrm{D}$ & $78.03 \pm 4.56$ & 78.65 & 69.95 & 83.61 & \\
\hline JL-JR (mm) CEPH & $65.00 \pm 11.69$ & 70.00 & 44.50 & 76.50 & \multirow{2}{*}{$\mathrm{P}<.02^{*}$} \\
\hline JL-JR (mm) 3D & $58.96 \pm 7.04$ & 59.04 & 42.54 & 67.68 & \\
\hline Nasal width (mm) CEPH & $29.32 \pm 3.47$ & 29.00 & 24.00 & 34.50 & \multirow{2}{*}{$\mathrm{P}<.000^{* * *}$} \\
\hline Nasal width $(\mathrm{mm}) 3 \mathrm{D}$ & 23.433 .48 & 22.48 & 19.79 & 31.73 & \\
\hline OcP-tilt (mm) CEPH & $1.14 \pm 0.84$ & 1.00 & 0.00 & 2.50 & \multirow{2}{*}{$P<.107 n s$} \\
\hline OcP-tilt (mm) 3D & $1.84 \pm 0.68$ & 1.95 & 1.02 & 3.12 & \\
\hline ZA-AZ (mm) CEPH & $128.73 \pm 10.66$ & 133.00 & 111.00 & 141.00 & \multirow{2}{*}{$\mathrm{P}<.000^{* * *}$} \\
\hline ZA-AZ (mm) 3D & $114.42 \pm 5.69$ & 116.79 & 103.00 & 120.62 & \\
\hline ZL-MoL $(\mathrm{mm}) \mathrm{CEPH}$ & $70.41 \pm 7.12$ & 66.50 & 60.50 & 82.00 & \multirow{2}{*}{$\mathrm{P}<.000^{* * *}$} \\
\hline ZL-MoL (mm) 3D & $60.83 \pm 4.40$ & 60.72 & 51.75 & 67.32 & \\
\hline ZR-MoR (mm) CEPH & $70.73 \pm 7.36$ & 67.00 & 60.00 & 84.00 & \multirow{2}{*}{$P<.000^{* * *}$} \\
\hline ZR-MoR (mm) 3D & $60.52 \pm 4.22$ & 61.26 & 54.04 & 68.34 & \\
\hline ZL-ZR (mm) CEPH & $93.59 \pm 9.65$ & 88.00 & 80.00 & 110.00 & \multirow{2}{*}{$\mathrm{P}<.022^{*}$} \\
\hline ZL-ZR (mm) 3D & $88.27 \pm 4.19$ & 89.29 & 82.19 & 94.56 & \\
\hline
\end{tabular}

Table 2. Comparison of 2D and 3D cephalometric evaluation for Mc Namara analysis.

\begin{tabular}{|c|c|c|c|c|c|}
\hline Parameters & Mean \pm Std. Dev & Median & Minimum & Maximum & test \\
\hline ANS-Me $(\mathrm{mm}) \mathrm{CEPH}$ & $58.18 \pm 7.37$ & 57.00 & 47.00 & 72.00 & \multirow{2}{*}{$\mathrm{P}<.54 \mathrm{~ns}$} \\
\hline ANS-Me $(\mathrm{mm}) 3 \mathrm{D}$ & $56.82 \pm 7.10$ & 56.54 & 47.91 & 69.05 & \\
\hline Co-A (mm) CEPH & $81.41 \pm 7.25$ & 82.50 & 71.00 & 91.00 & \multirow{2}{*}{$P<.01^{* *}$} \\
\hline Co-A $(\mathrm{mm}) 3 \mathrm{D}$ & $87.21 \pm 4.51$ & 89.15 & 80.26 & 93.60 & \\
\hline Co-Gn $(m m)$ CEPH & $104.14 \pm 6.75$ & 105.50 & 93.00 & 113.00 & \multirow{2}{*}{$P<.93$ ns } \\
\hline Co-Gn $(\mathrm{mm}) 3 \mathrm{D}$ & $104.09 \pm 4.37$ & 103.09 & 99.09 & 115.23 & \\
\hline Max-Mand (mm) CEPH & $22.23 \pm 6.62$ & 22.00 & 12.00 & 31.00 & \multirow{2}{*}{$\mathrm{P}<.02 *$} \\
\hline Max-Mand $(\mathrm{mm}) 3 \mathrm{D}$ & $16.87 \pm 3.87$ & 16.72 & 11.46 & 23.02 & \\
\hline SpPo-GoMe $\left({ }^{\circ}\right) \mathrm{CEPH}$ & $69.77 \pm 7.69$ & 70.00 & 56.00 & 80.00 & \multirow{2}{*}{$\mathrm{P}<.000^{* * *}$} \\
\hline SpPo-GoMe $\left(^{\circ}\right)$ 3D & $48.82 \pm 7.38$ & 47.45 & 37.21 & 65.82 & \\
\hline
\end{tabular}


ing landmarks in patients with severe maxillary or mandibulary defects, this information is critical for all orthognathic surgery patients, especially CLP patients. ${ }^{31}$

Leonardia et a ${ }^{32}$ have stated that it is generally easier to identify landmarks lying on a sharp curve or at the intersection of two curves than landmarks located on flat or broad curves. The same authors noted that points located in areas of high contrast are easier to identify than points located in areas of low contrast and that the mastoid, latero-orbitale and antegonion landmarks are easier to identify than dental landmarks. ${ }^{32}$

The statistically significant differences noted by Steiner analyses of SNGoGN and SNA measurements using $2 \mathrm{D}$ and $3 \mathrm{D}$ images in the present study may be related to the nature of the point Sella, one of the most important reference points. Although generally considered to be the center of a cephalometric view, Sella Turcica is, in fact, not a planar structure localized on the mid-cranial sagittal plane. This represents a significant difficulty in the assessment of the point Sella on conventional cephalometric film on three-dimensional reconstruction of computerized tomography scans. In line with this, Yitschaky et $\mathrm{a}^{33}$ found measurements involving Sella Turcica to vary significantly between $2 \mathrm{D}$ and $3 \mathrm{D}$ images, with the $3 \mathrm{D}$ location of the mid-sella point to be more precise using CT.
The distance from the condylion to Point A ICoA) represents the position of the maxilla in relation to the mandibular condyles. Even if we consider that the crest of the contour of maxillary anterior concavity in the lateral cephalogram can also be determined likewise as a point in the 3D reconstruction, the mandibular condyles are at a great distance from the sagittal mid-cranial plane. However, in lateral cephalograms, this distance is on a $2 \mathrm{D}$ plane they are neither in the in vivo situation nor in $3 \mathrm{D}$ reconstruction. Considering that it is nearly impossible to separately measure Co-A for the right and left condyles using cephalometric films, the present study calculated a mean value for the separate measurements obtained using 3D images and used this mean value to obtain an accurate comparison between $2 \mathrm{D}$ and $3 \mathrm{D}$ measurements. When considering the reference points in $3 \mathrm{D}$, we tried to reach to the nearest points corresponding to their $2 \mathrm{D}$ cephalometric landmarks in order to maximize the comparability of $2 \mathrm{D}$ and $3 \mathrm{D}$ measurements. It appears likely that $3 \mathrm{D}$ evaluation represents a more accurate method for monitoring craniofacial development than $2 \mathrm{D}$ lateral cephalometric films, especially among children with craniofacial deformities, where facial asymmetry is generally more pronounced.

Maeda et al ${ }^{10}$ suggested that 3D CT might have a higher sensitivity than PA cephalometric film

Table 3. Comparison of $2 \mathrm{D}$ and $3 \mathrm{D}$ cephalometric evaluation for Steiner analysis.

\begin{tabular}{|c|c|c|c|c|c|}
\hline Parameters & Mean \pm Std. Dev & Median & Minimum & Maximum & test \\
\hline SNA $\left.1^{\circ}\right) \mathrm{CEPH}$ & $75.86 \pm 6.44$ & 76.50 & 64.00 & 85.50 & \multirow{2}{*}{$\mathrm{P}<.007^{* *}$} \\
\hline SNA $\left.1^{\circ}\right)$ 3D & $77.17 \pm 5.61$ & 77.16 & 67.63 & 86.67 & \\
\hline SNB $\left(^{\circ}\right) \mathrm{CEPH}$ & $73.27 \pm 4.09$ & 75.00 & 64.00 & 77.00 & \multirow{2}{*}{$\mathrm{P}<.062 \mathrm{~ns}$} \\
\hline SNB $\left(^{\circ}\right) 3 \mathrm{D}$ & $74.52 \pm 3.14$ & 75.14 & 68.49 & 78.22 & \\
\hline ANB $\left.1^{\circ}\right) \mathrm{CEPH}$ & $2.59 \pm 4.72$ & 2.00 & -7.00 & 9.50 & \multirow{2}{*}{$\mathrm{P}<.036^{*}$} \\
\hline ANB $\left.1^{\circ}\right) 3 \mathrm{D}$ & $2.73 \pm 4.80$ & 2.72 & -7.57 & 11.62 & \\
\hline SND $\left.1^{\circ}\right) \mathrm{CEPH}$ & $70.68 \pm 3.99$ & 72.00 & 62.00 & 74.00 & \multirow{2}{*}{$\mathrm{P}<.11 \mathrm{~ns}$} \\
\hline SND $\left(^{\circ}\right) 3 D$ & $70.22 \pm 4.11$ & 71.75 & 59.77 & 73.63 & \\
\hline Max1-NA ( $\left.^{\circ}\right) \mathrm{CEPH}$ & $0.55 \pm 18.44$ & 6.00 & -42.00 & 24.00 & \multirow{2}{*}{$\mathrm{P}<.006 * *$} \\
\hline Max1-NA $\left.1^{\circ}\right) 3 D$ & $20.72 \pm 7.97$ & 17.73 & 11.81 & 37.63 & \\
\hline $\operatorname{Max} 1-\mathrm{SN}\left({ }^{\circ}\right) \mathrm{CEPH}$ & $75.91 \pm 17.42$ & 82.00 & 35.00 & 91.00 & \multirow{2}{*}{$\mathrm{P}<.286 \mathrm{~ns}$} \\
\hline $\operatorname{Max} 1-S N\left({ }^{\circ}\right) 3 D$ & $80.90 \pm 9.08$ & 84.42 & 63.14 & 89.56 & \\
\hline 1-1 $\left.1^{\circ}\right) \mathrm{CEPH}$ & $162.05 \pm 15.39$ & 156.50 & 148.00 & 192.00 & \multirow{2}{*}{$\mathrm{P}<.008^{* *}$} \\
\hline $\left.1-11^{\circ}\right) 3 D$ & $140.56 \pm 18.91$ & 140.40 & 109.37 & 170.41 & \\
\hline Mand1-NB $\left({ }^{\circ}\right) \mathrm{CEPH}$ & $17.18 \pm 6.25$ & 17.00 & 7.00 & 30.00 & \multirow{2}{*}{$\mathrm{P}<.005^{* *}$} \\
\hline Mand1-NB $\left({ }^{\circ}\right) 3 D$ & $21.62 \pm 7.40$ & 23.45 & 8.10 & 30.94 & \\
\hline SN-Go-Gn $\left(^{\circ}\right) \mathrm{CEPH}$ & $35.64 \pm 4.67$ & 35.00 & 30.00 & 45.00 & \multirow{2}{*}{$\mathrm{P}<.000^{* * *}$} \\
\hline SN-Go-Gn $\left(^{\circ}\right) 3 D$ & $48.27 \pm 3.31$ & 46.77 & 43.59 & 54.62 & \\
\hline
\end{tabular}


imaging in the diagnosis of maxillary asymmetry. For example, on PA cephalograms, it was not possible to evaluate anteroposterior asymmetry, for example, the distance between a landmark and the coronal reference plane, and the authors suggested that because 3D-CT permits more detailed evaluation, it has the potential to replace conventional cephalographic classification of facial asymmetry. ${ }^{10}$

With regard to intra- and inter-observer reliability, the degree of reported variation in landmark identification varies widely among studies. Major et al ${ }^{28}$ stated that landmarks with identification errors greater than $1.5 \mathrm{~mm}$ should probably be avoided and that landmarks with identification errors greater than $2.5 \mathrm{~mm}$ are definitely inappropriate for PA cephalograms. In the present study intra-observer variability was very high; however, the measurements should be analyzed carefully due to the differences found between the groups for clinical evaluation. Each individual landmark is known to have its own characteristic noncircular envelope of error, $29,34,35$ and, as Lou et al ${ }^{29}$ point out, differences in measurement of short linear distances will be reflected as greater percentages of error than similar absolute differences in measurement of longer distances. Similarly, for angular measurements, the absolute difference in measurement of an acute angle appears as a greater percent of error than that of a more obtuse angle.

In addition to landmark shape, measurement accuracy is also affected by defects and asymmetries. For example, in CLP patients, locating the deepest point of the maxilla (point $A$ ) is very difficult. Among the measurements obtained in the present study, the greatest errors were found for SNA angle and Co-A length. Imaging of the premaxillary region in $3 \mathrm{D}$ imaging is very different from imaging of 2D cephalometric films. In general, superimposition makes it difficult to accurately identify upper incisor position on cephalometric films, and in the present study, excessive inclination and rotation in CLP patients added to the difficulty of accurately determining the position of the upper incisors, which explains the statistically significant differences in maxillary incisor measurements between the 2D and 3D groups.

Other factors involved in landmark identification accuracy include clinical experience, ${ }^{28}$ the clarity of the definition used to describe the landmark, image quality, the geometry (straight or ovoid) of the object to be identified and the contrast between adjacent objects. ${ }^{36}$ In the present study, for instance, the deepest point of the maxilla (jugular point) used in frontal analysis appeared as a fossa in the 3D image, but as a point in the cephalometric films. Similarly, due to the 3D nature of the meatus acusticus externus, the point Porion appeared in different locations in the 2D and $3 \mathrm{D}$ images. This would explain the great variability between $2 \mathrm{D}$ and $3 \mathrm{D}$ measurements of the parameter SpPo-GoMe in the present study (Table 2). Another reason for this variability could be the fact that SpPo-GoMe is located in different tomographic planes, as discussed above.

Troulis et $\mathrm{al}^{37}$ stated that 3D-CT driven software has great potential for use in the diagnosis and analysis of congenital and acquired craniomaxillofacial skeletal deformities; for the calculation of vectors of surgical movement, localization of osteotomies and placement of distraction devices as part of surgical treatment planning; and, possibly, as a basis for a surgical navigation system. The CT images taken in the present study were used by plastic surgeons for treatment planning.

If standard and repeatable reference points can be obtained, 3D cephalometric evaluation can provide accurate data on craniofacial measurements, as other studies have suggested. ${ }^{38,39}$ However, major concerns continue to exist regarding their widespread usage. 1,2,5,12 First, CTs expose patients to considerably higher amounts of radiation than conventional cephalograms. This limits the number of CT scans that can be taken over short intervals to monitor craniofacial development, especially in growing children. Second, CT scans requires very expensive equipment, making the cost of an individual CT scan much more expensive than a lateral cephalogram. For this reason, CBCT seems likely to replace medical CT for use in orthodontics and plastic surgery in the near future. Perhaps most important, there is still a need for the establishment of widely accepted reference points and norms appropriate for 3D evaluation in order to facilitate the consistency of inter-method evaluation. 


\section{CONCLUSIONS}

This study found significant differences between measurements made on 2D and 3D images taken of CLP patients. Although there are some previous studies reporting that cephalometric and three-dimensional evaluations show a considerably well correlation, but one should be very careful when interpreting the results.

This can be due to the fact that the subjects of this study are consisted of children with cranio-facial anomalies while all the norms in conventional cephalometric analyses are considered on normal subjects.

Within the limitations of this study, it can be concluded that further studies are needed in order to more accurately determine the anatomical landmarks on the three dimensional reproduction and thus to establish new standards for 3D evaluations of CLP patients.

\section{ACKNOWLEDGEMENT}

This study was financially supported by the Scientific Research Foundation of Gazi University, Ankara, Turkey (grant no 03/2006-31).

\section{REFERENCES}

1. Kragskov J, Bosch G, Gyldensted C, Sindet-Pedersen S. Comparison of the reliability of craniofacial anatomic landmarks based on cephalometric radiographs and three-dimensional CT scans. Cleft Palate Craniofac J 1997;34:111116.

2. Kumar V, Ludlow J, Cevidanes LHS, Mol A. In vivo comparison of conventional and cone beam CT synthesized cephalograms. Angle Orthod 2008;78:873-879.

3. Katsumata A, Fujishita M, Maeda M, Ariji Y, Ariji E, Langlais RP. 3D-CT evaluation of facial asymmetry. Oral Surg Oral Med Oral Pathol Oral Radiol Endod 2005;99:212-220.

4. Krarup S, Darvann TA, Larsen P, Marsh JL, Kreiborg S. Three-dimensional analysis of Mandibular growth and tooth eruption. J Anat 2005;207:669-682.

5. Swennen GRJ, Schutyser F. Three-dimensional cephalometry: spiral multi-slice vs cone-beam computed tomography. Am J Orthod Dentofacial Orthop 2006;130:410-416.

6. Cevidanes LHS, Styner MA, Proffit R. Image analysis and superimposition of 3-dimensional cone-beam computed tomography models. Am J Orthod Dentofacial Orthop 2006;129:611-618.

7. Halazonetis DJ. From 2-dimensional cephalograms to 3-dimensional computed tomography scans. Am J Orthod Dentofacial Orthop 2005;127:627-637.
8. Adams GL, Gansky SA, Miller AJ, Harrell WE JR, Hatcher DC. Comparison between traditional 2-dimensional cephalometry and a 3-dimensional approach on human dry skulls. Am J Orthod Dentofacial Orthop 2004;126:395-396.

9. Nakamura N, Suzuki A, Takahashi H, Honda Y, Sasaguri M, Ohishi M. A longitudinal study on influence of primary facial deformities on maxillofacial growth in patients with cleft lip and palate. Cleft Palate Craniofac J 2005;42: 633-640.

10. Maeda M, Katsumata A, Ariji Y, Muramatsu A, Yoshida K, Goto S, Kurita K, Ariji E. 3D-CT evaluation of facial asymmetry in patients with maxillofacial deformities. Oral Surg Oral Med Oral Pathol Oral Radiol Endod 2006;102:382-390.

11. Alves PVM, Bolognese AM, Zhao L. Three-dimensional computerized orthognathic surgical treatment planning. Clin Plast Surg 2007;34:427-436.

12. Kitaura H, Yonetsu K, Kitamori H, Kobayashi K, Nakamura T. Standardization of 3-D CT measurements for length and angles by matrix transformation in the $3-D$ coordinate system. Cleft Palate Craniofac J 1999;37:349-356.

13. Moshiri M, Scarfe WC, Hilgers ML, Scheetz JP, Silveira AM, Farman AG. Accuracy of linear measurements from imaging plate and lateral cephalometric images derived from cone-beam computed tomography. Am J Orthod Dentofacial Orthop 2007;132:550-560.

14. Varghese S, Kailasam V, Padmanabhan S, Vicraman B, Chithranjan A. Evaluation of the accuracy of linear measurements on spiral computed tomography-derived three-dimensional images and its comparison with digital cephalometric radiography. Dentomaxillofacial Radiol 2010;39:216-223.

15. Singh GD, Levy-Bercowski D, Yanez MA, Santiago PE. Three-dimensional facial morphology following surgical repair of unilateral cleft lip and palate in patients after nasoalveolar molding. Orthod Craniofacial Res 2007;10:161166.

16. Duffy S, Noar JH, Evans RD, Sanders R. Three-dimensional analysis of the child cleft face. Cleft Palate Craniofac $J$ 2000;37:137-144.

17. Suri S, Utreja A, Khandelwal N, Mago SK. Craniofacial Computerized Tomography analysis of the midface of patients with repaired complete unilateral cleft lip and palate. Am J Orthod Dentofac Orthop 2008;134:418-429.

18. Feichtinger M, Zemann W, Mossböck R, Karcher H. Threedimensional evaluation of secondary alveolar bone grafting using a $3 \mathrm{D}$ navigation system based on computed tomography: a two year follow up. Br J Oral Maxillofac Surg 2008;46:278-282.

19. Yoon YJ, Kim DH, Yu PS, Kim HJ, Choi EH, Kim KW. Effect of head rotation on posteroanterior cephalometric radiographs. Angle Orthod 2002;72:36-42. 
20. Hsiao TH, Chang Hong-Po, Liu KM. A method of magnification correction for posteroanterior radiographic cephalometry. Angle Orthod 1997;67:137-142.

21. Gribel BF, Gribel MN, Manzi FR, Brook SL, McNamara Jr JA. From 2D to 3D : an algorithm to derive normal values for 3-dimensional computerized assessment. Angle Orthod 2011;81:5-12.

22. Van Vlijmen OJC, Maal TJJ, Berge SJ, Bronkhorst EM, Katsaros C, Kuijpers-Jagtman AM. A comparison between two-dimensional and three dimensional cephalometry on frontal radiographs and cone beam computed tomography scans of human skulls. Eur J Oral Science 2009;117:300305.

23. Houston WJ. The analysis of errors in orthodontic measurements. Am J Orthod 1983;83:382-390.

24. Ahlqvist J, Eliasson S, Welander U. The effect of projection errors on cephalometric length measurements. Eur J Orthod 1986:8:141-148.

25. Major PW, Johnson DE, Hesse KL, Glover KE. Effect of head orientation on posteroanterior cephalometric landmark identification. Angle Orthod 1996;66: 51-60.

26. Van Vlijmen OJC, Berge SJ, Swennen GRJ, Bronkhorst EM, Katsaros C, Kuijpers-Jagtman AM. Comparison of cephalometric radyographs obtained from cone beam computed tomography scans and conventional radiographs. J Oral Maxillaofac Surg 2009;67:92-97.

27. Malkoç S, Sarı Z, Üșümez S, Koyutürk AE. The effect of head rotation on cephalometric radiographs. Eur J Orhod 2005;27:315-321.

28. Major PW, Johnson DE, Hesse KL, Glover KE. Landmark identification error in posteroanterior cephalometrics. $A n$ gle Orthod 1996;64:447-454.

29. Lou L, Lagravere MO, Compton S, Major PV, Flores-Mir C. Accuracy of measurements and reliability of landmark identification with computed tomoraphy (CT) techniques in the maxillofacial area: a systematic review. Oral Surg Oral Med Oral Pathol Oral Radiol Endod 2007;104:402-411.

30. Hagg U, Cooke MS, Chan TC, Tng TT, Lau PY. The reproducibility of cephalometric landmarks: an experimental study on skulls. Aust Orthod J 1998;15:177-185.

31. Waitzman AA, Posnick JC, Armstrong DC, Pron GE. Craniofacial skeletal measurements based on computed tomography: Part I. Accuracy and reproducibility. Cleft Palate Craniofac J 1992;29:112-117.

32. Leonardia R, Annunziatab A, Caltabianoc M. Landmark identification error in posteroanterior cephalometric radiography. A systematic review. Angle Orthod 2008;78:761765.
33. Yitschaky O, Redlich M, Abed Y, Faerman M, Casap N, Hiller N. Comparison of common hard tissue cephalometric measurements between computed tomography $3 \mathrm{D}$ reconstruction and conventional 2D cephalometric images. Angle Orthod 2011;81:13-18.

34. Valeri CJ, Cole TM 3rd, Lele S, Richtsmeier JT. Capturing data from three-dimensional surfaces using fuzzy landmarks. Am J Phys Anthropol 1998;107:113-124.

35. Williams FL, Richtsmeier JT. Comparison of mandibular landmarks from computed tomography and 3D digitizer data. Clin Anat 2003;16:494-500.

36. Baumrind S, Frantz RC. The reliability of head film measurements. 1. Landmark identification. Am J Orthod 1971;60:111-127.

37. Troulis MJ, Everett P, Seldin EB, Kikinis R, Kaban LB. Development of a three-dimensional treatment planning system based on computed tomographic data. Int J Oral Maxillofac Surg 2002;31:349-357.

38. Richtmeier JT, Paik C, Elfert PC, Cole TM, Dahlman HR. Precision, repeatibility and validation of the localization of cranial landmarks using computed scans. Cleft-Palate Craniofac J 1995;32:217-227.

39. Cavalcanti MGP, Rocha SS, Vanier MW. Craniofacial measurements base on 3D-CT volume rendering implications for clinical applications. Dentomaxillaofac Radiol 2004;33:170-176. 